\title{
Distribution of Urease in Clostridium perfringens Types
}

\author{
BY M. ELIZABETH BROOKS \\ The Wellcome Research Laboratories, Beckenham, Kent, England
}

(Received 9 February 1961)

\begin{abstract}
SUMMARY
About five hundred strains of Clostridium perfringens were tested for ability to produce urease. There was found to be a distinct, although not complete, correlation between urease production and antigenic type. In types $B$ and $D$ there was also some degree of correlation between the production of urease and of $\lambda$-antigen. The distribution of urease between the six antigenic types of $C$. perfringens was not sufficiently sharp to be of use in type differentiation.
\end{abstract}

\section{INTRODUCTION}

Clostridium perfringens has been subdivided into six types: A to $\mathrm{E}$ distinguished by the production of one or more of the major lethal toxins $\alpha, \beta, \epsilon$ and $\iota$; and $\mathbf{F}$, which on the basis of toxin production would be included in type $\mathrm{C}$, distinguished mainly by heat resistance, large cell size and epidemiology (Wilsdon, 1931; Glenny et al. 1933; Oakley, Warrack \& Warren, 1948; Oakley, 1949; Ross, Warren \& Barnes, 1949; Zeissler \& Rassfeld-Sternberg, 1949). Each of these types, including F, is further characterized by the production of a number of minor antigens, enzymic in nature, and distinguished by their effects on appropriate substrates and by the neutralization of these effects by the corresponding type antisera. In the course of a general survey of the cultural and biochemical characteristics of various Clostridium spp. a number of $C$. perfringens strains was examined for ability to produce urease. Since some of these gave positive and others negative results, a large number of strains was examined to determine whether any correlation existed between urease production and antigenic type. The results of this survey, together with the results of experiments attempting to elucidate the nature of $C$. perfringens urease, are reported in this paper.

\section{METHODS}

Strains examined. Four hundred and ninety-two strains were examined, divided between types as follows: type A, 267 strains; type B, 63; type C, 64; type D, 68; type E, 10; and type F, 20 strains. Each of the ecological subtypes recognized within types B and C was represented (Brooks, Sterne \& Warrack, 1957), and the strains were drawn from a wide range of habitats, geographically widespread and including pathological and non-pathological sources. Classical and vaccine-production strains and freeze-dried and freshly isolated cultures were included in the survey.

Preparation of test material. Fifteen ml. amounts of Robertson's cooked meat medium in one ounce screw-cap bottles were inoculated from broth cultures, or 
with colonies picked from the surface of blood-agar plates, and incubated at $37^{\circ}$ for 18-24 $\mathrm{hr}$. Some strains were also grown in $57 \mathrm{ml}$. amounts of a similar medium, and samples tested after 5, 24, 48 and $72 \mathrm{hr}$. incubation.

Duplicate $3 \cdot 0 \mathrm{ml}$. samples from well-grown cultures were placed in small glass tubes and centrifuged. The supernatant fluids were discarded and the sediments washed once in $1.0 \%(\mathrm{w} / \mathrm{v})$ saline. The washed sediments were used for testing without any further processing or addition of preservatives. Some samples were given up to five further washings with $1.0 \%$ saline but in no case did this alter the final result of the test, and it was therefore concluded that the single washing was adequate.

Reagents. The reagent used for routine testing (solution $\mathbf{A}$ ) was a modified version of that used by Ferguson \& Hook (1943) and by Anderson (1945), and was made up as follows: $0.1 \mathrm{~g}$. $\mathrm{KH}_{2} \mathrm{PO}_{4} ; 0.1 \mathrm{~g} . \mathrm{K}_{2} \mathrm{HPO}_{4} ; 0.5 \mathrm{~g}$. NaCl; 2.0 g. urea; 0.5 g. phenol; $1.0 \mathrm{ml} .95 \%(\mathrm{v} / \mathrm{v})$ ethanol in water; $100 \mathrm{ml}$. distilled water; $5.0 \mathrm{ml}$. Universal Indicator (British Drug Houses Ltd., Poole); and sufficient $0 \cdot 1 \mathrm{~N}-\mathrm{HCl}$ to give an orange colour (about $\mathrm{pH} 6 \cdot 0$ ).

A control reagent (solution $\mathrm{B}$ ) in which the urea was replaced by a further $\mathbf{2 \cdot 0} \mathrm{g}$. $\mathrm{NaCl}$ was made up, and also both test and control reagents as above but omitting the Universal Indicator (solutions C and D, respectively).

Procedure for urease tests. For the routine test one of each pair of culture sediments was resuspended in $2.0 \mathrm{ml}$. of solution $\mathbf{A}$ and the other in the same volume of solution $\mathrm{B}$, and both suspensions were incubated at $37^{\circ}$ for $18 \mathrm{hr}$. The development of alkalinity, as indicated by a colour change to green or blue, in the solution $A$ tube only, was taken to indicate the presence of urease. None of the strains examined gave a positive reaction with solution $B$. Although the results of the test were not recorded until $18 \mathrm{hr}$. incubation, the colour change indicating the presence of urease developed within minutes in strongly urease-positive cultures and was evident in all positive suspensions after $2-4 \mathrm{hr}$. at $37^{\circ}$. Some tests showing negative results were incubated for up to $72 \mathrm{hr}$. but still showed no tendency to develop alkaline reactions.

For the Nessler's reagent test the sediments were resuspended in solutions $\mathrm{C}$ and $\mathrm{D}$, respectively, and incubated at $37^{\circ}$. Samples were removed after $18 \mathrm{hr}$. and tested for the presence of $\mathrm{NH}_{4}^{+}$by the addition of Nessler's reagent. The appearance of an orange-yellow precipitate, in the solution $\mathrm{C}$ test only, was taken to indicate urease production. No strain gave a precipitate with solution $\mathbf{D}$.

Suspensions of cultures subjected to ultrasonic disintegration were tested with both the routine and the Nessler's reagents. Equal volumes of suspension and reagent were incubated together at $37^{\circ}$ for $18 \mathrm{hr}$. and the results interpreted as described above.

Preparation of cell suspensions for ultrasonic disintegration. Seventy-five ml. amounts of a broth containing meat particles were inoculated and incubated at $37^{\circ}$ for $18 \mathrm{hr}$. After the meat particles had been strained off, the broths were centrifuged, the supernatant fluids discarded and the sediments washed in phosphate buffer $(\mathrm{pH} \mathrm{7 \cdot 3)}$ and finally resuspended in $10 \mathrm{ml}$. amounts of the same buffer. After the removal of a $2.0 \mathrm{ml}$. sample the remainder of each suspension was subjected to ultrasonic disintegration for $10 \mathrm{~min}$. (Mullard 500 watt E 7590-B disintegrator).

Preparation of urease suspensions for titration of anti-urease activity. Urease- 
positive cultures were grown for $18-24 \mathrm{hr}$. in $75 \mathrm{ml}$. amounts of meat broth, harvested, centrifuged, and the sediments washed in $1.0 \%$ saline and finally resuspended in $1.0 \%$ saline. These suspensions proved to be fairly stable and showed little change in urease activity after several days storage at $4 \cdot 0^{\circ}$.

Two dried urease preparations were obtained by drying washed bacteria harvested from 12 l. cultures of urease-positive type $\mathbf{B}$ and type $\mathbf{F}$ strains. The washed bacteria were dried in desiccators over silica gel and subsequently finely ground to give homogeneous preparations.

Sera. Antibacterial and antitoxic sera prepared by the hyperimmunization of horses, and antibacterial sera prepared by the hyperimmunization of rabbits, against urease-positive and urease-negative Clostridium perfringens strains, were tested for ability to inhibit the urease reaction. Normal horse and rabbit sera were used as controls. All the immune sera contained antibodies to the appropriate soluble antigens of $C$. perfringens. Two antibacterial sera prepared in rabbits against strains of the urease-producing $C$. sordellii were also tested.

Titration of sera for anti-urease activity. One ml. amounts of serial twofold dilutions of the sera under test were mixed thoroughly with $1.0 \mathrm{ml}$. amounts of suitable dilutions of the fresh or dried urease preparations, and allowed to stand at room temperature for $30 \mathrm{~min}$., after which $\mathbf{0 . 5} \mathrm{ml}$. of the routine urease reagent (solution A) was added to each mixture. The results of titrations, as increase in $\mathrm{pH}$ value, were recorded after $18 \mathrm{hr}$. incubation at $37^{\circ}$. Either $1.0 \%$ saline or distilled water was used as diluent, both giving the same results. The $\mathrm{pH}$ values were measured with a $\mathrm{pH}$-meter.

The rabbit sera were also titrated using constant volumes of serum and doubling dilutions of the urease preparation.

Test for inhibition of urease activity by urease-negative strains. Fifteen ml. amounts of Robertson's cooked meat broth were inoculated with pairs of the strains under test and incubated at $37^{\circ}$ for $24 \mathrm{hr}$. Smears of each culture were examined, and a culture sample was streaked on a blood agar plate and incubated anaerobically overnight, to determine the presence of growth from both inocula. In the Clostridium bifermentans/C. perfringens mixtures the examination of smears was sufficient for this purpose. In those $C$. perfringens mixtures where, even on plates, the two strains were indistinguishable, some colonies were picked into saline and tested for urease activity.

\section{RESULTS}

Distribution of urease production in Clostridium perfringens types

The results of the urease tests for strains of all types are shown in Table 1. Several strains were tested several times, both as replicate samples from one culture and as replicate cultures from one strain. In all cases the results for any one strain were consistent, even to the extent of giving approximately the same colour change where positive. In cultures incubated for $72 \mathrm{hr}$. the urease reactions were the same for 5, 24, 48 and $72 \mathrm{hr}$. samples. About 50 cultures were also tested with Nessler's reagent. All gave results which agreed with those for the routine test.

About one-fifth of the strains examined were found to produce urease, but this property was unevenly distributed between the various types and subtypes. All the type $\mathbf{C}$ strains examined were urease-negative. Type A was virtually urease- 
negative, having only six urease-producing strains. The urease-positive and ureasenegative type A strains were otherwise indistinguishable. Of the six urease-positive strains all were recently isolated, 5 from pathological material and the sixth from the intestines of a normal sheep. Whether or not this can be taken to indicate that type A strains tend to lose the capacity for urease production is doubtful, as numerous freshly isolated type A strains showed no tendency to produce urease. Only 10 type $\mathbf{E}$ strains were available for examination, and all of these were urease-positive. Of the 20 type $\mathbf{F}$ strains 13 produced urease, and, as in type $A$, the urease-positive resembled the urease-negative strains in respect of antigen production. The most interesting results were those obtained with the types $\mathbf{B}$ and $\mathbf{D}$ strains. In both these types there was a distinct correlation between the production of urease and of the $\lambda$-antigen (Table 2).

Table 1. Distribution of urease production in Clostridium perfringens types

\begin{tabular}{|c|c|c|c|c|}
\hline & \multirow[b]{2}{*}{ Type } & \multirow{2}{*}{$\begin{array}{c}\text { No. } \\
\text { strains } \\
\text { examined }\end{array}$} & \multicolumn{2}{|c|}{ Urease-positive strains } \\
\hline & & & No. & $\% *$ \\
\hline $\mathbf{A}$ & & 267 & 6 & $\mathbf{2}$ \\
\hline B & $\begin{array}{l}\text { Classical } \\
\text { Iranian }\end{array}$ & $\begin{array}{r}57 \\
6\end{array}$ & $\begin{array}{r}51 \\
0\end{array}$ & $\begin{array}{r}89 \\
0\end{array}$ \\
\hline C & $\begin{array}{l}\text { Classical } \\
\text { Colorado } \\
\text { Piglet }\end{array}$ & $\begin{array}{l}31 \\
22 \\
11\end{array}$ & $\begin{array}{l}\mathbf{0} \\
\mathbf{0} \\
\mathbf{0}\end{array}$ & $\begin{array}{l}\mathbf{0} \\
\mathbf{0} \\
\mathbf{0}\end{array}$ \\
\hline D & & 68 & 24 & 35 \\
\hline $\mathbf{E}$ & & 10 & 10 & 100 \\
\hline $\mathbf{F}$ & & 20 & 13 & 65 \\
\hline
\end{tabular}

Table 2. Urease and $\lambda$ production in types $\boldsymbol{B}$ and $\boldsymbol{D}$ strains

\begin{tabular}{|c|c|c|c|c|c|}
\hline & \multirow[b]{2}{*}{ Type } & \multirow[b]{2}{*}{$\lambda$ production } & \multirow{2}{*}{$\begin{array}{c}\text { No. } \\
\text { strains } \\
\text { examined }\end{array}$} & \multicolumn{2}{|c|}{ Urease-positive strains } \\
\hline & & & & No. & $\%^{*}$ \\
\hline B & Classical & $\begin{array}{l}\text { Unknown } \\
\text { + ve } \\
\text { - ve }\end{array}$ & $\begin{array}{r}8 \\
40 \\
9\end{array}$ & $\begin{array}{r}8 \\
\mathbf{3 7} \\
\mathbf{6}\end{array}$ & $\begin{array}{l}100 \\
92 \cdot 5 \\
67\end{array}$ \\
\hline B & Iranian & (all -ve) & 6 & $\mathbf{0}$ & $\mathbf{0}$ \\
\hline D & & $\begin{array}{l}\text { Unknown } \\
\text { + ve } \\
\text { - ve }\end{array}$ & $\begin{array}{l}20 \\
17 \\
31\end{array}$ & $\begin{array}{r}4 \\
16 \\
4\end{array}$ & $\begin{array}{l}20 \\
94 \\
13\end{array}$ \\
\hline
\end{tabular}

Urease and $\lambda$ production in type $B$ and $D$ strains

The production of $\lambda$-antigen is characteristic of the classical type $\mathbf{B}$ strains, and is one of the main points of difference between these and the Iranian subtype which is $\lambda$-negative. Of the $\mathbf{4 0}$ type $B$ strains known to produce $\lambda, \mathbf{3 7}$ produced urease also, whilst only 6 of the $9 \lambda$-negative classical type $B$ strains produced urease. The $\lambda$-negative 'Iranian' strains were all urease-negative. One of the ureasenegative classical strains was derived from a $\lambda$-positive urease-positive parent strain, and had lost the capacity for $\lambda$-production also. In type $\mathbf{D}$ the correlation 
between urease and $\lambda$-production was more marked, 16 of the $17 \lambda$-positive and only 4 of the $31 \lambda$-negative strains producing urease.

No similar correlation was observed between urease and the production of any other of the soluble antigens in any of the Clostridium perfringens types, except in so far as the major lethal antigens determine type differentiation.

\section{Ultrasonic disintegration}

It was thought that the difference between the urease-positive and ureasenegative strains might lie not in their ability to produce urease intracellularly, but in the release of the urease from the cells. Bacterial suspensions prepared from positive and negative strains were therefore tested for urease activity before and after ultrasonic disintegration. The urease reactions of the suspensions were in all cases the same before and after disintegration, and agreed with the results of previous tests carried out on the same strains. These results rendered untenable the theory that the differences between strains might lie in the ease of rupture or permeability of the cell walls, rather than in the actual production of urease.

\section{Antigenicity of Clostridium perfringens urease}

Some tests were carried out in an attempt to ascertain whether or not the urease produced by Clostridium perfringens was antigenic, in the hope that this would show whether the urease was type-specific, species-specific or non-specific. None of the sera tested specifically inhibited the activity of the urease preparations, although several of the sera caused apparent inhibition at low dilutions, presumably by buffering action tending to limit rise in $\mathrm{pH}$ value. This effect was observed with normal as well as immune sera. There was thus no evidence that $C$. perfringens urease is antigenic.

\section{Inhibition of urease activity by urease-negative strains}

In the course of a study on Clostridium bifermentans and $C$. sordellii it was noted that many strains of the urease-negative $C$. bifermentans were able to inhibit the positive urease reactions of $C$. sordelli strains when grown with them as mixed cultures, although this inhibition was not seen when cultures of the two species were mixed after growth (Brooks \& Epps, 1959). It seemed possible that the same phenomenon might occur with urease-positive and urease-negative $C$. perfringens cultures. Accordingly 45 mixed cultures of urease-positive and urease-negative C. perfringens strains, and two mixed cultures of urease-positive $C$. perfringens and urease-inhibitory $C$. bifermentans were grown and tested for urease activity. In no case was there any evidence of the inhibition of urease activity.

\section{DISCUSSION}

The fact that only about $20 \%$ of the strains examined, and only $2.0 \%$ of the type A strains, produced urease probably accounts for the omission of Clostridium perfringens from Huet \& Aladame's (1952) list of urease-producing anaerobes. Similarly it is not surprising that Ortali \& Samarani (1955) found the one C. perfringens strain they examined to be urease-negative.

It is unfortunate, from the point of view of pathological investigation, that the 
correlation between urease production and type differentiation is not complete. The most that can be said of the urease test as a tool in type differentiation is that since types $\mathrm{E}$ and $\mathbf{F}$ are rarely encountered, any Clostridium perfringens isolate producing urease can probably be assigned to types $\mathbf{B}$ or $\mathbf{D}$. The apparent correlation between urease and $\lambda$ production is similarly unhelpful as a diagnostic tool, but may, in the light of further investigations, help to elucidate the evolutionary relationships of the six $C$. perfringens types. Although the correlation is most marked in types $B$ and $D$, it is interesting to note that the $\lambda$-negative type $A$ was virtually urease-negative, and the $\lambda$-negative type $\mathrm{C}$ completely so, whilst in the urease-positive type $\mathbf{E}$ the five strains examined for $\lambda$ production were all found to be positive. It is only in the type $F$ strains, with their meagre range of soluble antigens and peculiarly limited distribution (all except one were isolated from cases of necrotic enteritis in Hamburg between 1946 and 1948, and the remaining one was isolated in the same place some years later), that the $\lambda$ /urease correlation breaks down. No type $F$ strain has been shown to produce $\lambda$, although when strains of this type were first isolated they were thought to elicit the production of small quantities of anti- $\lambda$ in hyperimmune horses and were, therefore, considered to be most nearly related to $C$. perfringens type B (Oakley, 1949). When the question of the position of type $\mathbf{F}$ was raised during a survey of $C$. perfringens antigen production, Brooks, Sterne \& Warrack (1957) considered type $\mathrm{F}$ to be related to type $\mathrm{C}$ rather than to type $B$, on the basis of the range of antigens produced by the three types, and Mrs I. Batty (personal communication) on retesting six of the original type $\mathbf{F}$ antisera, found little or no anti- $\lambda$ in three and only very small amounts comparable to those found in several normal sera, in the other three.

Since it is difficult to see how there can be any direct relationship between urease and $\lambda$, particularly since one sometimes occurs without the other, and yet their occurrence together seems too consistent to be purely fortuitous, their distribution may give some indication of the relationships between the various types and subtypes, and the sequence of evolution of the types if a common ancestor is assumed. In this connexion it is of interest that the distribution of urease production between types and subtypes, although not necessarily between individual strains, parallels that of a serum-dependent non- $\alpha \theta \delta$ haemolysis, observed only in cultures grown on blood-agar containing certain antisera (Brooks et al. 1957), although as with the soluble $\lambda$-antigen, the correlation between the production of urease and of the serum-dependent non- $\alpha \theta \delta$ haemolysis is not complete.

I wish to thank my colleagues at the Wellcome Research Laboratories for their help in various directions: Mrs I. Batty for the determination of antibody values in sera; Dr A. J. Woiwod and Dr A. W. Phillips for the ultrasonic disintegration of cultures; Mr H. Proom and the staff of the Culture Collection for the supply of freeze-dried cultures and access to their records; Miss C. Simpson and Mrs E. Williams for technical assistance; and Dr M. Sterne for help and guidance throughout this survey and in the preparation of the manuscript. 


\section{REFERENCES}

Anderson, T. G. (1945). A modification of the urease test for Proteus. Science, 101, 470. Brooks, M. E. \& Epps, H. B. G. (1959). Taxonomic studies of the genus Clostridium: Clostridium bifermentans and C. sordellii. J. gen. Microbiol. 21, 144.

Brooks, M. E., Sterne, M. \& Warrack, G. H. (1957). A re-assessment of the criteria used for type differentiation of Clostridium perfringens. J. Path. Bact. 74, 185.

Ferguson, W. W. \& Hook, A. E. (1943). Urease activity of Proteus and Salmonella organisms. J. Lab. clin. Med. 28, 1715.

Glenny, A. T., Barr, M., Llewellyn-Jones, M., Dalling, T. \& Ross, H. E. (1933). Multiple toxins produced by some organisms of the $\mathrm{Cl}$. welchii group. J. Path. Bact. 37, 53.

Huet, M. \& Aladame, N. (1952). Recherches sur l'uréase des bactéries anaérobies. Ann. Inst. Pasteur, 82, 766.

OAKLex, C. L. (1949). The toxins of C. welchii type F. Brit. med. J. i, 269.

OAkley, C. L., Warrack, G. H. \& Warren, M. E. (1948). The Kappa and Lambda antigens of Clostridium welchii. J. Path. Bact. 60, 495.

Ortali, V. \& Samarani, E. (1955). Micrometodi in microbiologia-1. Determinazione della ureasi. R.C. Ist. Sup. Sanit. 18, 1301.

Ross, H. E., WARren, M. E. \& Barnes, J. M. (1949). Clostridium welchii Iota toxin; its activation by Trypsin. J. gen. Microbiol. 3, 148.

Wilsdon, A. J. (1931). Observations on the Classification of Bacillus welchii. Rep. Dir. Inst. Anim. Path. Univ. Camb. 2, 53.

Zeissler, J. \& RAssfeld-Sternberg, L. (1949). Enteritis necroticans due to Clostridium welchii Type F. Brit med. J. i, 267. 